\title{
Soil resource dynamics in a changing world
}

\section{Other Conference Item}

Author(s):

Doetterl, Sebastian (D)

Publication date:

2020-05

Permanent link:

https://doi.org/10.3929/ethz-b-000462104

Rights / license:

Creative Commons Attribution 4.0 International

Originally published in:

EGUsphere, https://doi.org/10.5194/egusphere-egu2020-3445 
EGU2020-3445

https://doi.org/10.5194/egusphere-egu2020-3445

EGU General Assembly 2020

(c) Author(s) 2021. This work is distributed under

the Creative Commons Attribution 4.0 License.

\section{Soil resource dynamics in a changing world}

\section{Sebastian Doetterl ${ }^{1,2}$}

${ }^{1}$ ETH Zürich, Terrestrial Ecosystems, Environmental Systems Science, Zürich, Switzerland (sdoetterl@usys.ethz.ch)

${ }^{2}$ Augsburg University, Institute of Geography, Augsburg, Germany

Good time for soil scientists, bad time for soils? Join me at my Soil System Sciences - OECS award lecture where I will highlight how Global Change affects soils across ecosystems and what this means for future plant-soil interactions and biogeochemical cycles in a warming, crowded world out of balance.

Global Change from the Arctic to the Tropics has accelerated drastically in recent decades, subsequently effecting ecosystems everywhere. Soils and biogeochemical cycling within are no exception. For example, how carbon and nutrients are stabilized in and released from soil is highly affected by changing land use and climate. Despite these changes, soil in earth system models is not represented mechanistically, but rather given a mostly budgetary "black box" function. No methodological framework is available that accounts for the combined effects of climate, geochemistry and disturbance on soil dynamics at larger scales. In addition, most of our process understanding of biogeochemical cycling in soils is derived from data-rich temperate regions. This data has limited applicability in low latitudinal (tropics) or high latitudinal (boreal/subpolar) climate zones, where soils have different properties and drastically different developmental histories.

In my talk I will illustrate with a few examples how the gaps in our understanding of soil processes across climate zones and dismissing lateral soil fluxes leads to large uncertainties in predicting future trajectories of the global carbon cycle. I will highlight how the interactions of weathering and disturbance can influence and dominate biogeochemical cycles and microbial processes in soils. I will also discuss some directions where geochemical proxies that are available at the global scale can be useful to model the spatial and temporal patterns of soil carbon storage and turnover. 